\title{
Autosomal Recessive Limb Girdle Muscular Dystrophy In A Complex Consanguineous Family: The First Cases Series In Indonesia
}

\author{
Nydia Sihombing ${ }^{1}$, Nurin Aisyiyah Listyasari ${ }^{1}$, Sultana MH Faradz $^{2 *}$ \\ ${ }^{1}$ PhD student, Faculty of Medicine Diponegoro University Semarang, Indonesia \\ ${ }^{2}$ Division of Human Genetics, Center for Biomedical Research (CEBIOR) Faculty of Medicine Diponegoro \\ University Semarang, Indonesia
}

\section{Article Info}

History:

Received: 06 Sept 2017

Accepted: 22 Dec 2017

Available: 31 Dec 2017

\begin{abstract}
Background: Limb girdle muscular dystrophy (LGMD) is a neuromuscular abnormality with clinical heterogeneity and various severity, where over 30 subtypes have been identified. Meanwhile, molecular diagnosis of LGMD is not commonly carried out in Indonesia. We present a large pedigree of familial LGMD, with over 14 years of follow-up.

Case Presentation: A 12-year old female patient came with muscle weakness. She had toe walking since age of 6 , followed by calf hypertrophy for over three years. Family history revealed complex consanguinity. Her younger sister and her parents' cousin had similar condition, with the latter was already bedridden.

Physical examination results were waddling gait, lordotic spine, and absent deep tendon reflexes. Muscle biopsy showed sign of dystrophic process. Immunoperoxidase staining of some proteins resulted normal. Single nucleotide polymorphis $\mathrm{m}$ (SNP) array in two siblings revealed homozygosity on chromosome 15 containing CAPN3 gene of LGMD2A subtype.

Recently, the patient is wheelchair bound and undergoes rehabilitation. Her sister is still able to walk with abnormal gait, while her parents' cousin had passed away in age 55. From the multiple consanguinity, it could be concluded as autosomal recessive type LGMD.

Conclusion: A large family with LGMD from Indonesia was presented with more than 14 years of care. Clinical diagnos is was made based on physical and additional examination, however molecular analysis for establishing definitive diagnosis is still limited. Further studies such as targeted or whole exome sequencing is warranted to elucidate the cause of disease. Long-term evaluation and supportive care, in addition to proper counseling may increase quality of life.
\end{abstract}

Keywords: Limb girdle muscular dystrophy, case series, consanguinity, genetic counseling

\section{INTRODUCTION}

Limb girdle muscular dystrophy (LGMD) is a neuromuscular disorder with clinical heterogeneity and slow muscle deterioration progressivity. The overall prevalence of LGMD is estimated between 1 in 14,500 to 45,000 individuals, with more than 30 subtypes have been known related to various severity and phenotypic spectrums. LGMD1 is a form of autosomal dominant, with known subtypes including LGMD1A, LGMD1B, and LGMD1C. Meanwhile,
LGMD 2 consists of various subtypes from LGMD2A to LGMD2Q, and recently found subtypes with rare prevalence from LGMD2R to LGMD2W. The most prevalent subtype among all is LGMD2A, which compromise $26.5-30 \%$ of all LGMD cases and is inherited in autosomal recessive manner. ${ }^{1,2}$ The disorder is due to deficiency of calpain-3 protein that involves in sarcomere remodeling process in the muscle. ${ }^{3}$ Lack of calpain-3 may cause a significant 
* Corresponding author:

Sultana MH Faradz

Telp./Fax: +6224-8454714

E-mail: sultanafaradz@gmail.com

decrease in post-fusion incorporation of neonatal myosin heavy chain (nMHC), a developmental myogenic markers in muscle fiber regeneration. ${ }^{4}$ The molecular diagnosis scope of limb girdle muscular dystrophy is not commonly performed in Indonesia. Thus, the etiological diagnosis of many neurodegenerative disorders remains overlooked by the clinicians. Nevertheless, clinical and supportive care of the affected family member are equally important. We present a large pedigree of familial limb girdle muscular dystrophy, with more than 14 years history of follow-up. This case, to the best of our knowledge, is the first reported cases of familial LGMD in Indonesia.

\section{CAS E PRES ENTATION}

A 12-years old female patient with muscle weakness was referred to the Center for Biomedical Research (CEBIOR) in 2002 for a genetic testing and genetic counseling regarding her condition. Since she was 6 years old, she had toe walking and was unable to squat. The condition was followed by pseudo hypertrophy of the calves for over three years. Her walking gait deteriorated, despite of undergoing Achilles tendon lengthening surgery to improve feet posture and gait. She experienced fatigable weakness, had mild arm weakness and lordosis. There were no cardiovas cular or respiratory abnormalities.

Family history revealed complex consanguinity, in which her parents are of second cousins' marriage. Her younger sister had similar condition starting from age 7, while her parents' cousin had started toe walking since age 20 and was already bedridden at 49 years old. All three family members had elevated creatinine kinase $(\mathrm{CK})$ level, where index patient and her sister showed significantly higher level $(4,715$ $\mathrm{U} / \mathrm{L}$ and 13,545 U/L [normal female value $145 \mathrm{U} / \mathrm{L}$ ], respectively). Meanwhile, $\mathrm{CK}$ level of the uncle increased, but not as high as other family members upon checkup (278 U/L; normal male value $171 \mathrm{U} / \mathrm{L}$ ). Multiple consanguinity of the family is shown in Figure 1.

Physical examination revealed waddling gait, lordotic spine, and absent deep tendon reflexes, while other findings were unremarkable. Muscle biopsy showed sign of dystrophic process. Immunoperoxidase studies were performed on some proteins, i.e. Dystrophin 1, Dystrophin 2, Dystrophin 3, Merosin, Adhalin, Beta Sarcoglycan, Gamma Sarcoglycan, Beta Dystroglycan, Emerin, Caveolin, and Dysferlin. All staining resulted in normal staining. SNP array on two siblings were carried out, with no copy number variations (CNVs) found. Meanwhile, further analysis revealed homozygosity on chromosome 15q15.1 (GRCh38) containing CAPN3 gene, which produces calpain-3 protein of LGMD2A subtype.

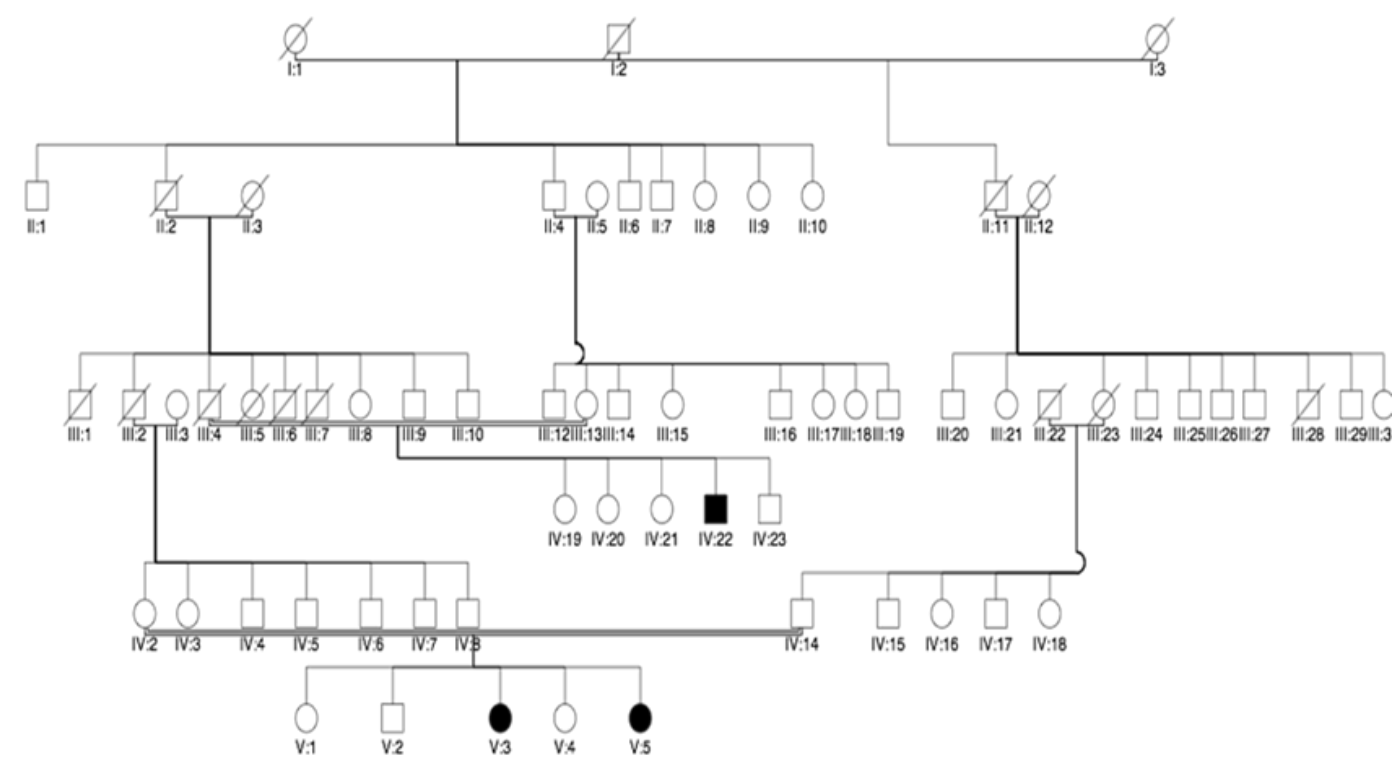

Figure 1. Pedigree of family member with limb girdle muscular dystrophy. V:3 is index case with suspected LGMD2A. V:5 is her younger sister with starting similar condition. IV:22 is her uncle (parents' cousin) who was bedridden. 
Her younger sister occasionally walked on her toes, and received routine physiotherapy. There was no difficulty on going up on a staircase. Meanwhile, her uncle had started toe walking at 20 years old. By the time of examination, he was already bedridden.

Upon the latest follow up, the patient is now 26 years old. She has already graduated from university, and is now wheelchair bound. Her younger sister is still able to walk with abnormal gait, while her parents' cousin has passed away in age of 59 years old. The patient received short term steroid treatment, and until recently, she still undergoes physiotherapy.

\section{DISCUSS ION}

The most plausible subtype of LGMD2A in this patient is first demonstrated by the multiple consanguinity in the family, which explains the autosomal recessive inheritance. LGMD2A onset ranges from 2 to 40 years old, with the average of 815 years old. ${ }^{2}$ In this case, the age of onset were 6 years old (index case), 9 years old (proband sibling), and 20 years old (proband uncle). Loss of ambulation typically occurred from 5 to 39 years. The long range of onset and slow progressivity distinguished this case to other autosomal recessive LGMD subtypes.On LGMD2B cases, there is similarly slow progressivity (10-20 years) but with different muscle involvement. Meanwhile in LGMD2C, there is a rapid progressivity similar to Duchenne muscular dystrophy. ${ }^{1}$ Differences between subtypes of LGMD2 are shown on Table 1.

Table 1. Various subtypes of autosomal recessive LGMD. The clinical features, type of muscle weakness and age onset, along with probable involvement of protein showed LGMD2A as the most possible cause of disorder.

\begin{tabular}{|c|c|c|c|c|}
\hline $\begin{array}{l}\text { LGMD2 } \\
\text { subtype }\end{array}$ & Clinical features & Muscle weakness & Age onset & Protein involvement \\
\hline LGMD2A & $\begin{array}{l}\text { No cardiac involvement, CK level } \\
\text { varies }\end{array}$ & Proximal & $2-40$ y ears & Calpain \\
\hline LGMD2B & $\begin{array}{l}\text { Slow progressivity, no } \\
\text { cardiomy opathy, very high CK } \\
\text { level }\end{array}$ & $\begin{array}{l}\text { Distal and/or pelvic } \\
\text { femoral }\end{array}$ & $17-23$ years & Dysferlin \\
\hline $\begin{array}{l}\text { LGMD2C, D, } \\
\text { E, F }\end{array}$ & $\begin{array}{l}\text { Severe progressivity, cardiac and } \\
\text { respiratory involvement, very high } \\
\text { CK }\end{array}$ & Proximal & $3-15$ years & Sarcogly can \\
\hline LGMD2G & $\begin{array}{l}\text { Foot drop, moderately high CK } \\
\text { level }\end{array}$ & Proximal and distal & $9-15$ years & Telethonin \\
\hline LGMD2H & Facial weakness, waddling gait & Proximal & $1-9$ years & Tripartite motif containing 32 \\
\hline LGMD2I & $\begin{array}{l}\text { Respiratory failure, } \\
\text { cardiomy op athy, my algia }\end{array}$ & Proximal & $1.5-27$ years & Fukutin related protein \\
\hline LGMD2J & $\begin{array}{l}\text { Cardiac and respiratory } \\
\text { involvement }\end{array}$ & Proximal and distal & $5-25$ years & Titin \\
\hline LGMD2K & $\begin{array}{l}\text { Mild weakness, intellectual } \\
\text { disability }\end{array}$ & Proximal & $1-3$ years & Protein-O-mannosyl transferase \\
\hline LGMD2L & $\begin{array}{l}\text { Predominantly affects male, no } \\
\text { cardiac involvement }\end{array}$ & $\begin{array}{l}\text { Proximal pelvic } \\
\text { femoral/distal lower } \\
\text { limbs }\end{array}$ & $\begin{array}{l}\text { Late teens- } \\
50 \text { years }\end{array}$ & Anoctamin 5 \\
\hline LGMD2M & $\begin{array}{l}\text { Mild intellectual disability, } \\
\text { cardiomy op athy }\end{array}$ & Axial and proximal & $\begin{array}{l}4 \text { months- } 4 \\
\text { years }\end{array}$ & Fukutin \\
\hline LGMD2N & Calf hypertrophy & Proximal & 18 months & Protein-O-mannosyl transferase 2 \\
\hline LGMD2O & Calf hypertrophy, severe myopia & Proximal & 12 years & $\begin{array}{l}\text { Protein-O-linked mannose } \beta 1,2 \\
\text { N-acety lglucosaminyl transferase }\end{array}$ \\
\hline LGMD2P & $\begin{array}{l}\text { Intellectual disability, } \\
\text { microcephaly, respiratory failure, } \\
\text { cardiomy op athy }\end{array}$ & Proximal & $\begin{array}{l}\text { First to the } \\
\text { fourth } \\
\text { decade of } \\
\text { life }\end{array}$ & Dystrogly can \\
\hline LGMD2Q & Delayed motor milestone & Proximal & $2-3$ years & Plectin \\
\hline
\end{tabular}


LGMD2A is caused by missense, splice site, frameshift, or nonsense mutation on calpain-3 gene (CAPN3) which located in 15q15-21. A missense mutation in the exon 22 of calpain-3 gene was shown in three cases of Brazilian and Amish consanguineous families. 5 This region was particularly found homozygous in the two siblings, suggestive to the same cause of disorder. Phenotype manifestations are mainly in proximal muscles involvement, with specific biopsy results commonly found. There is no facial, cardiac, and respiratory involvement on the LGMD2A subtype. ${ }^{6}$

In this case, the uncle has lower level of CK serum (278 U/L) compared to other affected members, in the age of 45 years old. In the LGMD2A patients, CK serum is typically raised to 3-20 times higher than normal level. Decreasing CK serum level may be caused by the progressivity of disease and the increasing activity of muscle cell degeneration. ${ }^{4}$

\section{CONCLUSION}

A large family with LGMD from Indonesia was presented with over 14 years of follow-up, which included physical examination, laboratory workups, rehabilitation and genetic counseling. Clinical diagnosis was made based on physical and additional examination, however molecular analysis for establishing definitive diagnosis is still limited. This case emphasizes the importance of genetic testing and counseling in Indonesia, especially in patients with neurodegenerative disorders, where diagnostic workup remains as a challenge. To establish LGMD2A diagnosis, or to elucidate other possible cause of disease and protein involvement, further studies such as targeted sequencing on $C A P N 3$ gene or whole exome sequencing are warranted. Our longterm evaluation and supportive care, in addition to proper genetic counseling may enhance the family quality of life. Proper diagnosis may shed light to future prevention on next generation, and may increase the efficacy of genetic counseling.

\section{ACKNOWLEDGEMENTS}

We would like to thank Dr. Heather M Johnston and Dr. Tony Roscioli from Sydney Children's Hospital for their contribution in clinical and molecular analysis.

\section{REFERENCES}

1. Wicklund MP, Kissel JT. The limb-girdle muscular dystrophies. Neurol Clin. 2014;32(3):729-49.

2. Murphy AP, Straub V. The Classification, Natural History and Treatment of the Limb Girdle Muscular Dystrophies. J Neuromuscul Dis. 2015;2(s2):S7-19.

3. Fanin M, Angelini C. Protein and genetic diagnosis of limb girdle muscular dystrophy type 2A: The yield and the pitfalls. Muscle and Nerve. 2015;52(2):163-73.

4. Hauerslev S, Sveen M-L, Duno M, Angelini C, Vissing J, Krag TO. Calpain 3 is important for muscle regeneration: evidence from patients with limb girdle muscular dystrophies. BMC Musculoskelet Disord. 2012;13(1):43.

5. Richard I, Broux O, Allamand V, Fougerousse F, Chiannilkulchai N, Bourg N, et al. Mutations in the proteolytic enzyme calpain 3 cause limbgirdle muscular dystrophy type 2A. Cell. 1995;81(1):27-40.

6. Pegoraro E, Hoffman EP. Limb-Girdle Muscular Dystrophy Overview. GeneReviews(®). University of Washington, Seattle; 1993. 